Polymer Journal, Vol. 38, No. 12, pp. 1251-1257 (2006)

(C) 2006 The Society of Polymer Science, Japan

\title{
Isothermal Crystallization Behavior of the Poly(L-lactide) Block in Poly(L-lactide)-Poly(ethylene glycol) Diblock Copolymers: Influence of the PEG Block as a Diluted Solvent
}

\author{
Junliang YANG, Ting ZHAO, Leijing LiU, Yunchun ZHOU, \\ Gao LI, ${ }^{\dagger}$ Enle ZHOU, and Xuesi CHEN \\ State Key Laboratory of Polymer Physics and Chemistry, Changchun Institute of Applied Chemistry, \\ Graduate School of Chinese Academy of Sciences, Chinese Academy of Sciences, Changchun 130022, P. R. China
}

(Received August 11, 2006; Accepted September 25, 2006; Published November 2, 2006)

\begin{abstract}
Isothermal crystallization kinetics and morphology of the poly(L-lactide) block in poly(L-lactide)poly(ethylene glycol) diblock copolymers were studied by differential scanning calorimetry (DSC) and polarized optical microscopy (POM), respectively. The results were compared with that of the PLLA homopolymer. The introduction of the PEG block accelerated the crystallization rate of the PLLA block and promoted to form ring-banded spherulites. The analysis of isothermal crystallization kinetics has shown that the PLLA homopolymer accorded with the Avrami equation. But the PLLA block of the diblock copolymers deviated from the Avrami equation, which resulted from increasing of the crystallization rate and occurring of the second crystallization process. The equilibrium melting temperature $\left(T_{\mathrm{m}}^{o}\right)$ of the PLLA block fell with its molecular weight decreasing. The conditions to obtain more regular ring-banded spherulites were below: the sample was the PLLA block of $\mathrm{LA}^{5} \mathrm{EG}^{5}$; the crystallization temperature was about from $95^{\circ} \mathrm{C}$ to $100^{\circ} \mathrm{C}$, which almost corresponded to regime II. [doi:10.1295/polymj.PJ2006094]

KEY WORDS Isothermal Crystallization / Diluted Solvent / PLLA Block / PEG Block / Ring-banded Spherulites /
\end{abstract}

Poly(L-lactide)(PLLA) is possessed of many predominant properties, such as biodegradability, biocompatibility, innocuity, tissue absorbability and so on. Therefore, it is widely used in medical $\operatorname{area}^{1-4}$ as an important biomaterial. But it also has some flaws. For example, bad watersolubility, friability etc. Moreover, the properties are not able to meet the demand for expandedness of its application area. In order to improve its property, the synthesis of PLLA-based block copolymer is one of the most important ways. Poly(ethylene glycol) (PEG) is the simplest polyether. It has good biocompatibility, blood-compatibility, hydrophilicity and flexibility. ${ }^{5,6}$ Hydrophilic PEG is introduced to form block copolymer which hopes to improve hydrophilicity, biocompatibility and other properties. ${ }^{7-10}$ Therefore, PLLA-PEG block copolymers have attracted many researchers' attention and have been studied on their properties and application. ${ }^{11-15}$

Although crystallization process of block copolymer that have double-crystallizable blocks is more complex than other block copolymer systems, the studies on crystallization process and morphology also attracted many people's attention in recent years owing to their important meaning in practical application. ${ }^{16-19}$ As a double-crystallizable block copolymer, it is out of question that the properties and application of PLLA-PEG block copolymers have intimate rela- tions with their crystallization process, crystallinity and crystallization morphology. Therefore, studying them is the indispensable contents. Fujiwara conducted detailed investigation on the crystallizationinduced morphological change, macromolecular selforganization process and crystalline structure. ${ }^{20-22}$ Lee reported that PLLA and PEG blocks were phase separated, and the crystallization behavior of one block was markedly affected by the presence of the other block. ${ }^{23}$ Luo thought that the crystallization morphology was deeply dependent on the composition for PEO/PLLA multiblock copolymers. ${ }^{24}$ Recently, Shin carried out studies on the morphology of PLLA-PEG tribock copolymers and indicated that the PLLA and PEG crystals adopt the same average orientation. ${ }^{25}$

But the influence of the melting PEG block as a diluted solvent on the crystallization process of the PLLA block is unclear. The crystallization temperature of the PLLA "hard" block is higher than the melting temperature of the PEG "soft" block. During the crystallization process of the PLLA block, the system of PLLA-PEG block copolymer changes from amorphous-amorphous state to amorphous-semicrystalline state. Moreover, the PLLA block bonds chemically with the PEG block. Therefore, the presence of the melting PEG block influences the crystallization process of the PLLA block inevitably. In our previous

${ }^{\dagger}$ To whom correspondence should be addressed (Fax: +86-431-5262126, E-mail: ligao@ciac.jl.cn). 
paper, the confined crystallization behavior and melting behavior of the PEG block in PLLA-PEG diblock copolymers were studied. ${ }^{26}$ In the present study, our attention is to study the crystallization kinetics and morphology of the PLLA block in PLLA-PEG diblock copolymers under isothermal conditions by differential scanning calorimetry (DSC) and polarized optical microscopy (POM), and compare with the PLLA homopolymer.

\section{EXPERIMENTAL}

\section{Synthesis of the PLLA-PEG Diblock Copolymers}

PLLA-PEG diblock copolymers were prepared by the ring-opening copolymerization of L-lactide (supplied by Purac) in the presence of monomethoxy-terminated poly(ethylene glycol), which has one methyl group and the number average molecular weight of 5000 (supplied by Aldrich), catalyzed by stannous octoate $\left(\mathrm{Sn}(\mathrm{Oct})_{2}, 10 \mathrm{~mol} \%\right.$ relative to $\left.\mathrm{PEG}\right)$ according to the method reported earlier. ${ }^{27}$ The molecular weight and the polydispersity, $M_{\mathrm{w}} / M_{\mathrm{n}}$, were determined by GPC (Waters 410). The copolymer composition was evaluated by ${ }^{1} \mathrm{H}$ NMR (Unity-400). Molecular weight of the PLLA block in the copolymer was determined from the copolymer composition on the basis of the PEG's molecular weight. PLLA homopolymer was prepared by polymerization of LA catalyzed by $\mathrm{Sn}(\mathrm{Oct})_{2}$ using an alcohol as initiator. The molecular weight and composition of PLLA-PEG diblock copolymers together with PLLA homopolymer that used for experiments are listed in Table I.

\section{Wide-Angle X-Ray Diffraction (WAXD)}

One-dimensional (1D) WAXD measurement (Rigaku, D/max 2500V PC X-ray scattering) was carried out with a $\mathrm{Cu} K \alpha$ radiation $(\lambda=0.154 \mathrm{~nm})$. The scanning rate is $8^{\circ} / \mathrm{min}$ from 5 to $40^{\circ}$. Selected voltage and current were $50 \mathrm{kV}$ and $250 \mathrm{~mA}$, respectively. Each sample was heated to $175^{\circ} \mathrm{C}$ at the rate of $10^{\circ} \mathrm{C} / \mathrm{min}$ and keep at this temperature for $5 \mathrm{~min}$ (the samples were melted completely) under nitrogen

Table I. Molecular weight, polydispersity and composition of PLLA-PEG diblock copolymers and PLLA homopolymer

\begin{tabular}{lrccc}
\hline \multicolumn{1}{c}{ Sample } & $\begin{array}{c}\text { PLLA } \\
/ M_{\mathrm{w}}\end{array}$ & $\begin{array}{c}\text { PEG } \\
/ M_{\mathrm{w}}\end{array}$ & $\begin{array}{c}\text { Polydispersity } \\
M_{\mathrm{w}} / M_{\mathrm{n}}\end{array}$ & $\begin{array}{c}\text { PLLA } \\
\text { percent }\end{array}$ \\
\hline $\mathrm{LA}^{9}$ & 9000 & & 1.20 & $100 \%$ \\
$\mathrm{LA}^{15} \mathrm{EG}^{5}$ & 15000 & 5000 & 1.31 & $75 \%$ \\
$\mathrm{LA}^{5} \mathrm{EG}^{5}$ & 5000 & 5000 & 1.25 & $50 \%$ \\
$\mathrm{LA}^{2.5} \mathrm{EG}^{5}$ & 2500 & 5000 & 1.17 & $33.3 \%$ \\
\hline
\end{tabular}

${ }^{\mathrm{a}} \mathrm{LA}=$ poly(L-lactide) $($ PLLA), EG = poly(ethylene glycol) (PEG), and superscripts indicate the average number molecular weight in $\mathrm{kg} / \mathrm{mol}$. purge. Then cooling at the rate of $5^{\circ} \mathrm{C} / \mathrm{min}$ and scanning at the selected temperature.

\section{Differential Scanning Calorimetry (DSC)}

Isothermal crystallization behavior of the PLLA block in diblock copolymers and the neat PLLA homopolymer was measured by differential scanning calorimetry (DSC-7 and Pyris 1, from Perkin-Elmer) under nitrogen purge. Each sample of about $8 \mathrm{mg}$ was heated to $175^{\circ} \mathrm{C}$ at the rate of $10^{\circ} \mathrm{C} / \mathrm{min}$ and kept at this temperature for $5 \mathrm{~min}$. And then the samples were cooled to the designated crystallization temperature $\left(T_{\mathrm{c}}\right)$ quickly $\left(-100^{\circ} \mathrm{C} / \mathrm{min}\right)$ for isothermal crystallization. The heat flow during crystallization process was recorded as a function of time. The relative crystallization, $X_{\mathrm{t}}$, as a function of time is defined as:

$$
X_{\mathrm{t}}=\frac{\int_{t_{o}}^{t}\left(d H_{c} / d T\right) d T}{\int_{t_{o}}^{t_{\infty}}\left(d H_{c} / d T\right) d T}
$$

$t_{o}$ and $t_{\infty}$ are the time at which crystallization starts and ends, respectively.

\section{Polarized Optical Microscopy (POM)}

Morphology of spherulites was observed under crossed polarizers using POM (Linkam TM 600) under nitrogen purge. The samples used for observation of the POM were prepared by casting $1 \%(\mathrm{~g} / \mathrm{mL})$ chloroform solution on a clean microscope coverslide, and drying for a day at room temperature to remove the residual solvent. The dried samples melted at $175^{\circ} \mathrm{C}$ for $5 \mathrm{~min}$, then cooled to the isothermal crystallization temperature $\left(T_{\mathrm{c}}>60^{\circ} \mathrm{C}\right)$ quickly $\left(-100^{\circ} \mathrm{C} / \mathrm{min}\right)$ and kept at that temperature for $30 \mathrm{~min}$. The POM observation was carried out at $T_{\mathrm{c}}$.

\section{RESULTS AND DISCUSSION}

\section{WAXD Analysis}

According to our previous report, ${ }^{26}$ the crystal of PLLA block is $\alpha$-phase (pseudo-orthorhombic) and the crystal of PEG block is monoclinic crystal form. For the PLLA block, $2 \theta$ at $14.8^{\circ}, 16.8^{\circ}, 19.1^{\circ}$ and $22.2^{\circ}$, the planes are (011), (110) or (200), (113) or (203), and (210), respectively. For the PEG block, the planes of (110), (120) and (032) correspond to $2 \theta$ at $15^{\circ}, 19.1^{\circ}$, and $23.2^{\circ}$, respectively. Figure 1 has shown that when the samples' temperature is at $60^{\circ} \mathrm{C}$, there are only diffraction peaks of the PLLA block, but no diffraction peaks for the PEG block. As the temperature falls to $27^{\circ} \mathrm{C}$, the diffraction peaks of the PEG block of $\mathrm{LA}^{2.5} \mathrm{EG}^{5}$ and $\mathrm{LA}^{5} \mathrm{EG}^{5}$ emerge except for $\mathrm{LA}^{15} \mathrm{EG}^{5}$. But the diffraction peaks of the 


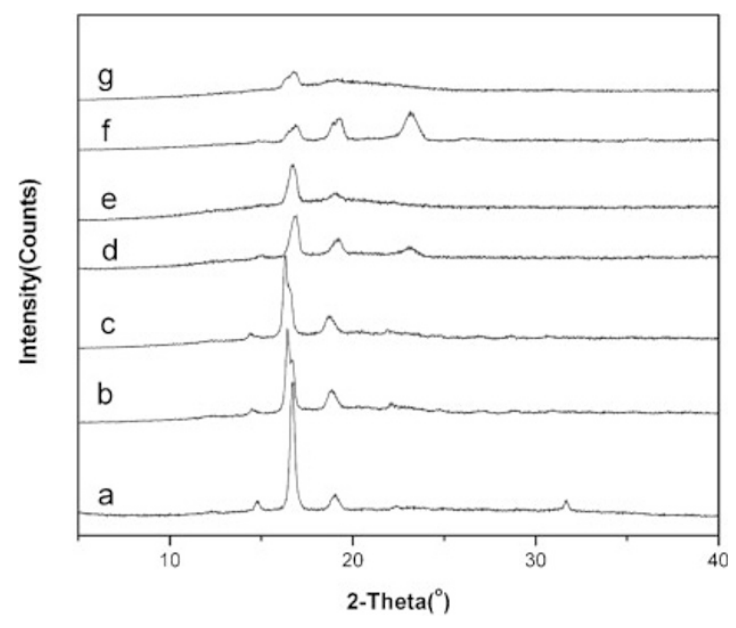

Figure 1. The WAXD curves of the PLLA-PEG diblock copolymers and PLLA homopolymer. a: $\mathrm{LA}^{9}$ at $27^{\circ} \mathrm{C}$; b: $\mathrm{LA}^{15} \mathrm{EG}^{5}$ at $27^{\circ} \mathrm{C}$; c: $\mathrm{LA}^{15} \mathrm{EG}^{5}$ at $60^{\circ} \mathrm{C}$; d: $\mathrm{LA}^{5} \mathrm{EG}^{5}$ at $27^{\circ} \mathrm{C}$; e: $\mathrm{LA}^{5} \mathrm{EG}^{5}$ at $60^{\circ} \mathrm{C}$; f: $\mathrm{LA}^{2.5} \mathrm{EG}^{5}$ at $27^{\circ} \mathrm{C}$; g: $\mathrm{LA}^{2.5} \mathrm{EG}^{5}$ at $60^{\circ} \mathrm{C}$.

PEG block of $\mathrm{LA}^{15} \mathrm{EG}^{5}$ can also be obtained when temperature falls to about $-20{ }^{\circ} \mathrm{C} .{ }^{26}$ They prove that both blocks are able to crystallize. Moreover, the PEG block is melt completely and presents as the melting solvent when the temperature is above $60^{\circ} \mathrm{C}$.

\section{Isothermal Crystallization Kinetics}

As is known, Avrami theory ${ }^{28}$ has been widely and successfully used to interpret isothermal crystallization process for polymers. The Avrami equation is:

$$
1-X_{\mathrm{t}}=\exp \left(-K t^{n}\right)
$$

Where $X_{\mathrm{t}}$ is the relative crystallinity, $t$ is the isothermal crystallization time, the exponent $n$ is the mechanism constant whose value depends on the type of nucleation and growth dimension. The parameter $K$ is a growth rate constant involving both nucleation and growth rate parameters. Using Avrami equation in double-logarithmic form, and plotting $\log [-\ln (1-$ $\left.X_{\mathrm{t}}\right)$ ] against $\log t$ for each isothermal crystallization process, a straight line is obtained from which values of the two adjustable parameters, $K$ and $n$, can be obtained. According to the experimental data of the isothermal crystallization curves, the Avrami plots of the PLLA homopolymer and the PLLA block of diblock copolymers are shown in Figure 2, and kinetics parameters are summarized in Table II.

Generally speaking, polymer crystallization is made up of two processes: primary crystallization and secondary crystallization. One of the simplified assumptions in Avrami model is no secondary crystallization process. Figure 2 a shows a good linear relation which indicates that the Avrami equation can be used to describe the isothermal crystallization process of the PLLA homopolymer. Because it needs more time to accomplish the isothermal crystallization process
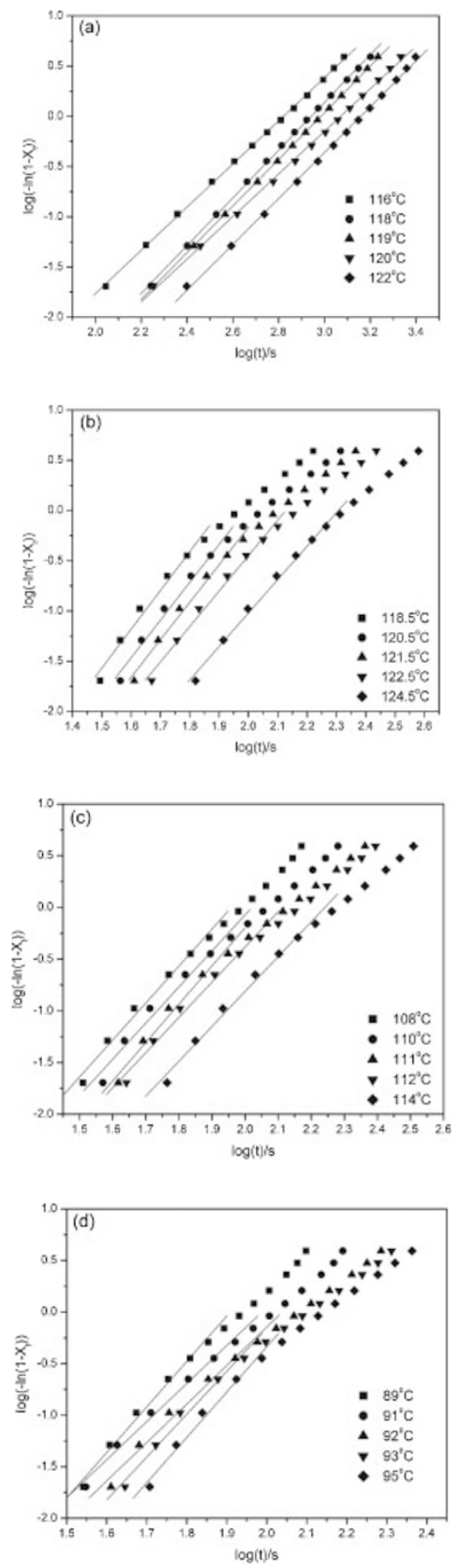

Figure 2. Avrami plots of $\log \left[-\ln \left(1-X_{\mathrm{t}}\right)\right]$ versus $\log t$ of the PLLA block of diblock copolymers and PLLA homopolymer at different temperature: (a) $\mathrm{LA}^{9}$, (b) $\mathrm{LA}^{15} \mathrm{EG}^{5}$, (c) $\mathrm{LA}^{5} \mathrm{EG}^{5}$, (b) $\mathrm{LA}^{2.5} \mathrm{EG}^{5}$.

and secondary crystallization process may do not occur under our experimental conditions. But no good linear relation is received in Figures $2 b-d$. It suggests that the introduction of the PEG block has influence on the crystallization of the PLLA block. As is shown in Figure 1, the PEG block is melt completely when temperature is over $60^{\circ} \mathrm{C}$. Therefore, the PEG block of samples is used as a diluted solvent during crystallization process of the PLLA block. The effect of diluted solvent quickens the crystallization of the PLLA block. The secondary crystallization that caused by the spherulite impingement in the later stage of crystallization process has occurred. Using the reciprocal 
Table II. Characteristic parameters of the PLLA block of diblock copolymers and PLLA homopolymer during isothermal crystallization process

\begin{tabular}{|c|c|c|c|c|c|c|}
\hline Sample & $\begin{array}{c}T_{\mathrm{c}} \\
\left({ }^{\circ} \mathrm{C}\right)\end{array}$ & $n$ & $\begin{array}{c}-\log K \\
\left(\min ^{-1}\right)\end{array}$ & $\begin{array}{c}t_{1 / 2} \\
(\mathrm{~min})\end{array}$ & $\begin{array}{c}1 / t_{1 / 2} \\
\left(\min ^{-1}\right)\end{array}$ & $\begin{array}{c}\Delta E \\
(\mathrm{KJ} / \mathrm{mol})\end{array}$ \\
\hline \multirow{5}{*}{$\mathrm{LA}^{9}$} & 116 & 2.5 & 6.066 & 9.40 & 0.106 & \multirow{5}{*}{-195.046} \\
\hline & 118 & 2.7 & 6.992 & 12.34 & 0.081 & \\
\hline & 119 & 2.6 & 6.930 & 13.78 & 0.073 & \\
\hline & 120 & 2.4 & 6.511 & 15.00 & 0.067 & \\
\hline & 122 & 2.6 & 7.214 & 18.53 & 0.054 & \\
\hline \multirow{5}{*}{$\mathrm{LA}^{15} \mathrm{EG}^{5}$} & 118.5 & 3.9 & 7.363 & 1.00 & 1.000 & \multirow{5}{*}{-221.829} \\
\hline & 120.5 & 3.8 & 7.478 & 1.23 & 0.813 & \\
\hline & 121.5 & 3.7 & 7.627 & 1.41 & 0.709 & \\
\hline & 122.5 & 3.5 & 7.498 & 1.70 & 0.588 & \\
\hline & 124.5 & 3.3 & 7.677 & 2.64 & 0.379 & \\
\hline \multirow{5}{*}{$\mathrm{LA}^{5} \mathrm{EG}^{5}$} & 108 & 3.6 & 7.003 & 1.07 & 0.935 & \multirow{5}{*}{-131.999} \\
\hline & 110 & 3.5 & 7.050 & 1.33 & 0.752 & \\
\hline & 111 & 3.7 & 7.598 & 1.54 & 0.649 & \\
\hline & 112 & 3.4 & 7.198 & 1.67 & 0.599 & \\
\hline & 114 & 3.4 & 7.557 & 2.19 & 0.457 & \\
\hline \multirow{5}{*}{$\mathrm{LA}^{2.5} \mathrm{EG}^{5}$} & 89 & 4.4 & 8.419 & 1.17 & 0.855 & \multirow{5}{*}{-66.061} \\
\hline & 91 & 3.7 & 7.3293 & 1.30 & 0.769 & \\
\hline & 92 & 3.8 & 7.539 & 1.33 & 0.752 & \\
\hline & 93 & 4.2 & 8.472 & 1.33 & 0.752 & \\
\hline & 95 & 4.4 & 9.127 & 1.55 & 0.645 & \\
\hline
\end{tabular}

of the half-time of crystallization $\left(1 / t_{1 / 2}\right)$ reflects crystallization rate, the results are shown in Table II. The crystallization rate of the PLLA block is about 10 times to that of the PLLA homopolymer, and the higher the crystallization temperature is, the more slowly they crystallize. The same result is also obtained according to their spherulites growth rate. From Table II, it also indicates that the average values of the Avrami exponents $(\bar{n})$ for primary crystallization are 2.6, 3.6, 3.5 and 4.1 for LA $^{9}$, the PLLA block of $\mathrm{LA}^{15} \mathrm{EG}^{5}, \mathrm{LA}^{5} \mathrm{EG}^{5}$ and $\mathrm{LA}^{2.5} \mathrm{EG}^{5}$, respectively. The exponent $n$ is the mechanism constant, whose value depends on the type of nucleation and growth dimension. Typical $n$ values for polymer spherulitic crystallization are 3 or 4 . The $n=3$ indicates three-dimensional spherulitic growth from instantaneous nuclei (athermal nucleation), and $n=4$ is interpreted as three-dimensional spherulites growing from sporadic nuclei (thermal nucleation). If crystallization occurs in two-dimensional aggregates (like axialites or lamellar aggregates), then $n=2$ or $n=3$ are expected depending on whether the nucleation is instantaneous or sporadic. ${ }^{29}$ Another simplified assumption in the Avrami model is constant radial growth rate $(\mathrm{G}=\mathrm{dr} / \mathrm{dt}$ or $\mathrm{r}=\mathrm{Gt})$. Its precondition is that crystallization rate $(\mathrm{R})$ is determined by nucleation rate (i). But the relation of $r=\mathrm{Gt}^{1 / 2}$ is obtained when $\mathrm{R}$ is determined by substrate completion rate $(\mathrm{g})$, and it makes the Avrami exponent $n$ be nonintegral. ${ }^{30}$ There-

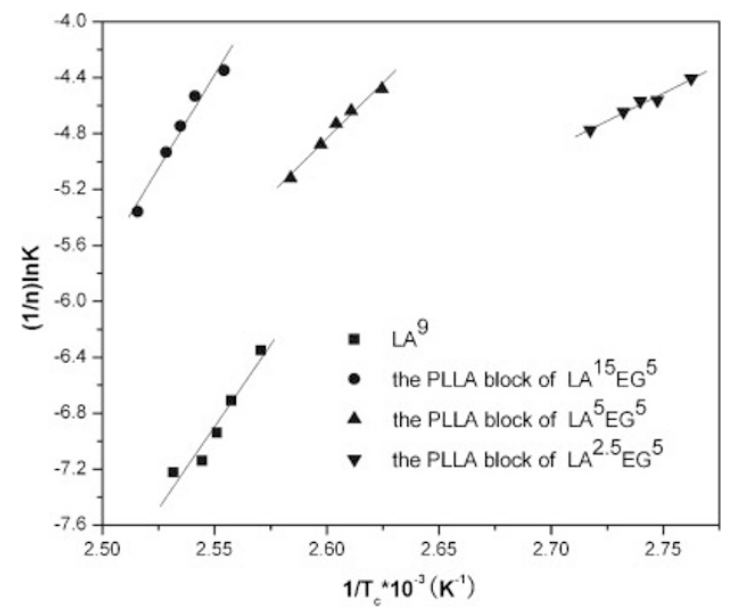

Figure 3. The plots of $(1 / \mathrm{n}) \ln \mathrm{K}$ versus $1 / T_{\mathrm{c}}$ according to the Arrhenius mothod for the PLLA block of diblock copolymers and PLLA homopolymer.

fore, $\bar{n}=2.6$ implies a three-dimensional spherulitic growth from athermal nucleation, and $\bar{n}=3.6,3.5$, 4.1 implies three-dimensional spherulites growing from thermal nucleation.

The isothermal crystallization process of the samples is assumed to be thermally activated, therefore the Avrami parameter $K$ can be approximately described by Arrhenius form: ${ }^{31}$

$$
\begin{aligned}
& K^{1 / n}=k_{0} \exp \left(-\frac{\Delta E}{R_{0} T_{\mathrm{c}}}\right) \\
\Rightarrow \quad & \ln K / n=\ln k_{0}-\frac{\Delta E}{R_{0} T_{\mathrm{c}}}
\end{aligned}
$$

Where $k_{0}$ is a temperature-independent pre-exponential factor and $R_{0}$ is the gas constant of $8.314 \mathrm{~J} /$ ( $\mathrm{mol} \mathrm{K})$. The isothermal crystallization activation energy $(\Delta E)$ are shown in Table II, which is from the slope of the plot of $\ln K / n$ versus $1 / T_{\mathrm{c}}$ (in Figure 3). They indicate that $\Delta E$ of the PLLA block is bigger than that of PLLA homoplymer except for that of $\mathrm{LA}^{15} \mathrm{EG}^{5}$, and $\Delta E$ of the PLLA block becomes bigger with the content of the PEG block increasing. It implies that the content of the PEG block as diluted solvent should be appropriate, or else the crystallization of the PLLA blocks will become difficult with the content of diluted solvent increasing. During their crystallization process, the PLLA block always bonds chemically with the PEG block. So the PLLA blocks should pull the PEG block to move, and some energy is consumed. The higher the percent of PEG block is, the more the energy should be consumed.

The equilibrium melting temperature $\left(T_{\mathrm{m}}^{o}\right)$ is an important thermodynamic parameter for characterizing a given crystal of a flexible linear polymer. The Hoffman-Weeks equation ${ }^{32}$ has been widely used to estimate the equilibrium melting temperature of poly- 


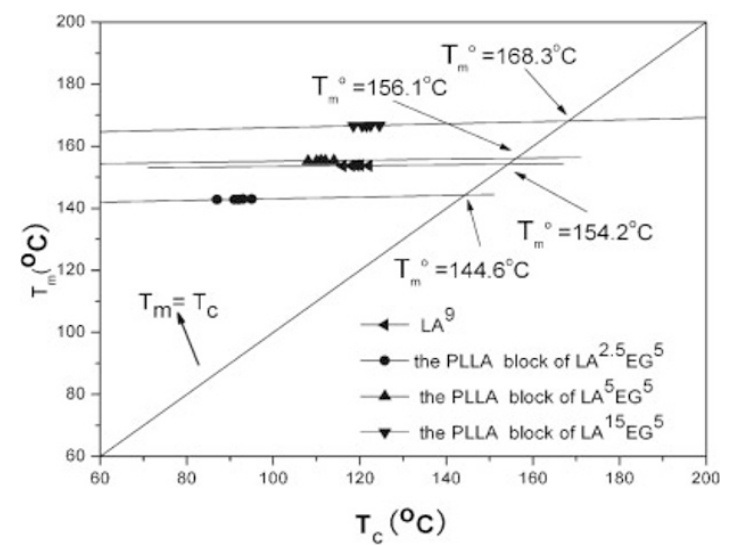

Figure 4. Determination of $T_{\mathrm{m}}^{o}$ for the PLLA block and PLLA homopolymer by the Hoffman-Weeks approach.

mers. $T_{\mathrm{m}}^{o}$ cann't be measured directly, but it can be deduced from the DSC measurements by the poltting of the observed apparent $T_{\mathrm{m}}$ and $T_{\mathrm{c}}$, and $T_{\mathrm{m}}^{o}$ can be obtained by means of the intersection to the resulting straight line with the line of $T_{\mathrm{m}}=T_{\mathrm{c}}$. They are shown in Figure 4 , and $T_{\mathrm{m}}^{o} \mathrm{~s}$ are $154.2{ }^{\circ} \mathrm{C}, 168.3^{\circ} \mathrm{C}, 156.1^{\circ} \mathrm{C}$, $144.6^{\circ} \mathrm{C}$ for $\mathrm{LA}^{9}$, the PLLA block of $\mathrm{LA}^{15} \mathrm{EG}^{5}$, $\mathrm{LA}^{5} \mathrm{EG}^{5}$ and $\mathrm{LA}^{2.5} \mathrm{EG}^{5}$, respectively. It is very evident that $T_{\mathrm{m}}^{o}$ of the PLLA block depresses with its mo- lecular weight decreasing. But $T_{\mathrm{m}}^{o}$ of $\mathrm{LA}^{9}$ is smaller than $T_{\mathrm{m}}^{o}$ of the PLLA block of $\mathrm{LA}^{5} \mathrm{EG}^{5}$, while the molecular weight of $\mathrm{LA}^{9}$ is bigger than that of the PLLA block of $\mathrm{LA}^{5} E G^{5}$. It suggests that introduction of the PEG block makes $T_{\mathrm{m}}^{o}$ increasing, which may result from more perfect crystals for the PLLA block of $\mathrm{LA}^{5} \mathrm{EG}^{5}$.

\section{Isothermal Crystallization Morphology}

Figure 5 shows the spherulite morphology of the samples at different temperature (some POM images are not shown). They were recorded at the crystallization temperature. The spherulitic size becomes bigger and bigger as degree of supercooling alters from large to small. The PLLA homopolymer forms well-defined spherulites that exhibit the classical maltese-cross extinction pattern during the crystallization temperature region under our experimental conditions (Figures 5a and $5 b$ ). There was a report about the PLLA homopolymer which was able to form ring-banded spherulites under special conditions, ${ }^{33}$ for example, crystallization after annealing at very higher temperature. But only common spherulites were obtained via the direct isothermal crystallization procedure. It is interesting that the PLLA block is easy to form ring-banded
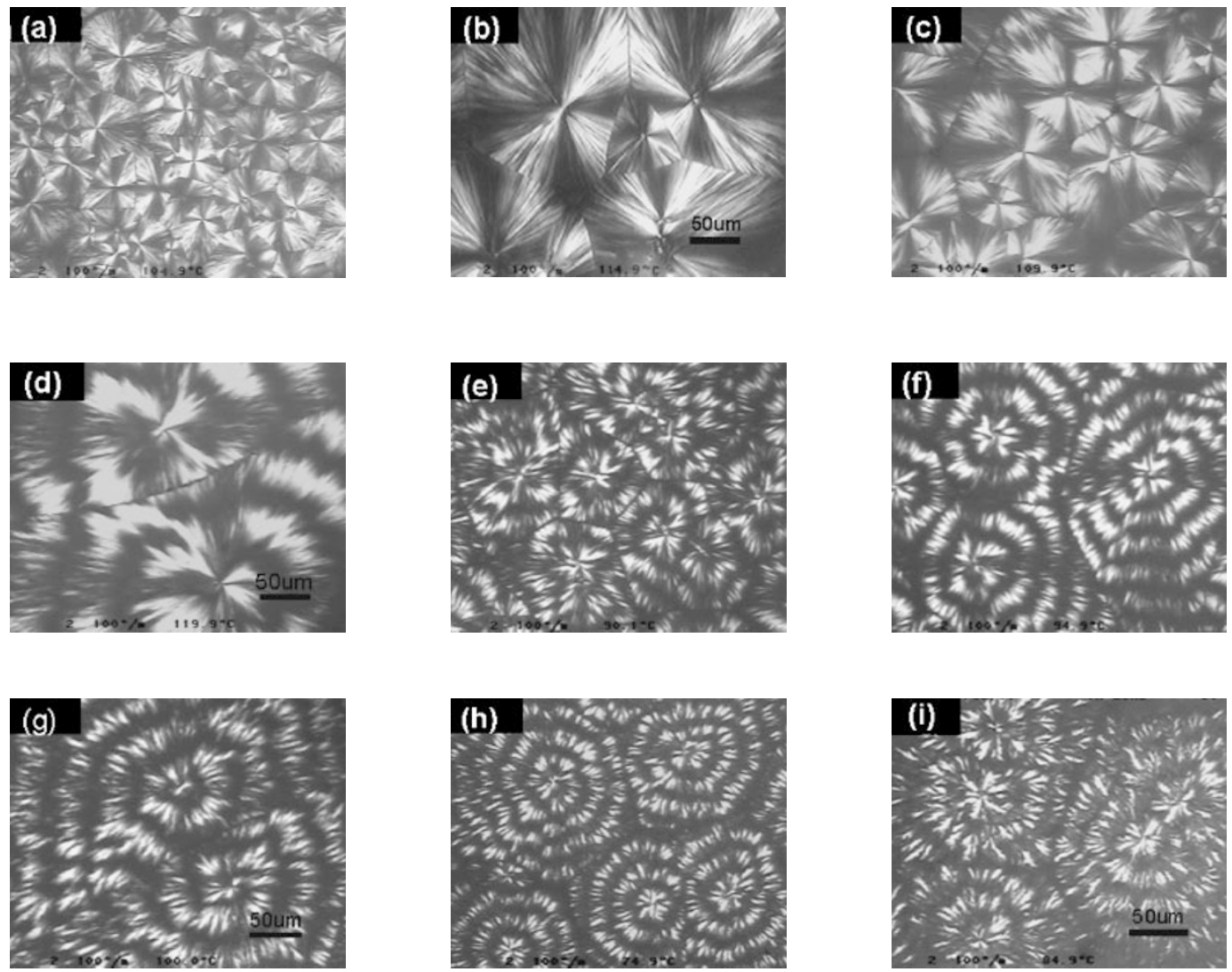

Figure 5. Polarized optical micrographs showing crystal morphology of PLLA homopolymer and the PLLA block of diblock copolymers during isothermal crystallization. (a) $\mathrm{LA}^{9}$, crystallization at $105^{\circ} \mathrm{C}$; (b) $\mathrm{LA}^{9}, 115^{\circ} \mathrm{C}$; (c) $\mathrm{LA}^{15} \mathrm{EG}^{5}, 110^{\circ} \mathrm{C},(\mathrm{d}) \mathrm{LA}^{15} \mathrm{EG}^{5}, 120^{\circ} \mathrm{C}$; (e) $\mathrm{LA}^{5} \mathrm{EG}^{5}, 90^{\circ} \mathrm{C}$; (f) $\mathrm{LA}^{5} \mathrm{EG}^{5}, 95^{\circ} \mathrm{C}$; (g) $\mathrm{LA}^{5} \mathrm{EG}^{5}, 100^{\circ} \mathrm{C}$; (h) $\mathrm{LA}^{2.5} \mathrm{EG}^{5}, 75^{\circ} \mathrm{C}$; (i) $\mathrm{LA}^{2.5} \mathrm{EG}^{5}, 85^{\circ} \mathrm{C}$. The images of the same sample at different temperature have the same scale bar. 
spherulites via the direct isothermal crystallization when the PEG block is introduced (Figures 5d-5i). For the PLLA block of $\mathrm{LA}^{15} \mathrm{EG}^{5}$, it is not able to form ring-banded spherulites at large degree of supercooling $\left(T_{\mathrm{c}}=105^{\circ} \mathrm{C}\right)$. But ring-banded spherulites can be obtained gradually as the degree of supercooling becomes small $\left(T_{\mathrm{c}}>=110^{\circ} \mathrm{C}\right)$. Figure $5 \mathrm{c}$ shows a tendency of forming ring-banded spherulites at $110^{\circ} \mathrm{C}$. The PLLA blocks of $\mathrm{LA}^{5} \mathrm{EG}^{5}$ and $\mathrm{LA}^{2.5} \mathrm{EG}^{5}$ are able to form ring-banded spherulites in the range of crystallization temperature. Moreover, ring-banded spherulites of $\mathrm{LA}^{5} \mathrm{EG}^{5}$ are more regular than that of $\mathrm{LA}^{2.5} \mathrm{EG}^{5}$ and $\mathrm{LA}^{15} \mathrm{EG}^{5}$. They suggest that the presence of the PEG block as a diluted solvent plays an importance role for forming ring-banded spherulites. The relative content of diluted solvent should be appropriate, more or less will be disadvantage to form ring-banded spherulites. The PEG block as melting solvent induces the PLLA block to crystallize. Furthermore, it provides a solvent environment for forming ring-banded spherulites. As already mentioned, ${ }^{34}$ the solvent induces the molecular motion of the amorphous polymer chains, indicating that the solvent dissolves the polymer chains and plays as a kind of plasticizer. Previous report ${ }^{35}$ has proved that the PLLA block and the PEG block are miscible each other at melting state. The motion of the activated chains causes the generation of the crystalline nuclei. As annealing time increasing, the crystalline nuclei grow up and the molecular chains of the PLLA block begin to fold and crystallize. At the same time, the molecular chains of the PEG block are expelled gradually onto the surface of the PLLA crystal. The crystallization process of the PLLA block is that diblock copolymer systems change from amorphous-amorphous state (miscible-melting state) to amorphous-semicrystalline state.

Another characteristic of the ring-banded spherulites is that the average value of periodic distance of extinction rings (the white extinction rings and the ray extinction rings) increases with crystallization temperature increasing. The results are shown in Table III. Ring-banding is an extinction pattern observed between crossed polars and optically caused by a zero birefringence effect. ${ }^{36}$ As for the forming mechanism of ring-banded spherulites, three mechanisms are reported: 1) the lamellar periodic twisting mechanism along spherulite radii; ${ }^{37}$ 2) transverse screw dislocation mechanism; ${ }^{38}$ 3) rhythmic crystal growth mechanism. ${ }^{39}$ The ring-banded spherulites are attested as the lamellar periodic twisting mechanism for most systems. $\mathrm{Xu}^{33}$ also proved that the periodical bands in the PLLA homopolymer, which were obtained under special conditions, do result from lamellar twisting by AFM.
Table III. Extinction rings distance of ring-banded spherulites for the PLLA block of diblock copolymers under isothermal crystallization conditions

\begin{tabular}{cccc}
\hline Sample & $T_{\mathrm{c}}\left({ }^{\circ} \mathrm{C}\right)$ & $\mathrm{D}_{\mathrm{w}}{ }^{\mathrm{a}}(\mu \mathrm{m})$ & $\mathrm{D}_{\mathrm{g}}{ }^{\mathrm{b}}(\mu \mathrm{m})$ \\
\hline & 105 & - & - \\
$\mathrm{LA}^{15} \mathrm{EG}^{5}$ & 110 & - & - \\
& 115 & - & - \\
& 120 & $32.5-37.5$ & $25.0-30.2$ \\
& 125 & $42.5-47.5$ & $25.2-27.6$ \\
\hline & 90 & $16.6-21.4$ & $9.5-14.3$ \\
$\mathrm{LA}^{5} \mathrm{EG}^{5}$ & 95 & $17.2-22.4$ & $11.9-16.7$ \\
& 100 & $23.8-28.6$ & $11.9-16.7$ \\
& 105 & $38.1-42.9$ & $16.7-21.4$ \\
& 110 & $42.5-50.0$ & $26.2-30.8$ \\
\hline & 70 & $10.6-14.8$ & $6.4-10.6$ \\
$\mathrm{LA}^{2.5} \mathrm{EG}^{5}$ & 75 & $14.8-19.1$ & $8.5-12.7$ \\
& 80 & $14.8-20.2$ & $8.5-12.7$ \\
& 85 & $23.3-27.5$ & $12.7-16.9$ \\
& 90 & $53.0-57.2$ & $23.3-27.5$ \\
\hline
\end{tabular}

a) $D_{w}$ is the white extinction rings distance. b) $D_{g}$ is the gray extinction rings distance.

Hoffman thought that degree of supercooling is a very important factor to determine spherulite morphology. ${ }^{40}$ According to crystallization theory of Laurizen-Hoffman, ${ }^{41}$ regime I, II and III are determined by nucleation rate (i) and substrate completion rate $(\mathrm{g})$ : regime I $(\mathrm{i} \ll \mathrm{g})$, regime II $(\mathrm{i}-\mathrm{g})$, regime III $(\mathrm{i} \gg \mathrm{g}$ ). At high crystallization temperature (low degree of supercooling), crystallization rate is controlled by the nucleation rate, which is regime I. While at low crystallization temperature (large degree of supercooling), crystallization rate is controlled by the substrate completion rate, which is regime III. Crystallization rate of regimes II is controlled by nucleation rate and substrate completion rate simultaneously, which is at the middle region of crystallization temperature. From Figures 5c-5i and some unshown images, the condition for forming more regular ring-banded spherulites is the temperature of middle region, which almost corresponds to regime II. In another words, regime II is advantage to obtain ring-banded spherulites for the PLLA block of diblock copolymers.

\section{CONCLUSIONS}

Both blocks of PLLA-PEG diblock copolymers were able to crystallize, but the PEG block was melt completely and presented as the melting solvent during crystallization process of the PLLA block. The isothermal crystallization behavior of the PLLA block in PLLA-PEG diblock copolymers and the PLLA hompolymer was different. The introduction of the PEG block accelerated the crystallization rate of the PLLA block and promoted to form ring-banded spher- 
ulites. The analysis of isothermal crystallization kinetics has shown that the PLLA homopolymer accorded with Avrami equation. But the PLLA block of the diblock copolymers deviated from Avrami equation, which resulted from increasing of the crystallization rate and occurring of the second crystallization process. The equilibrium melting temperature $\left(T_{\mathrm{m}}^{o}\right)$ of the PLLA block fell as its molecular weight decreasing. The spherulites morphology suggested that the PLLA block of diblock copolymers was able to form ring-band spherulites while the PLLA homopolymer wasn't. The average value of periodic distance of extinction ring increased with crystallization temperature increasing. In order to obtain more regular ringbanded spherulites, the sample was the PLLA block of $\mathrm{LA}^{5} \mathrm{EG}^{5}$ and the crystallization temperature was about from $95^{\circ} \mathrm{C}$ to $100^{\circ} \mathrm{C}$, which almost corresponded to regime II.

Acknowledgment. This work was supported by the fund of the Major Direction Program of the Sciential Inovation Project of Chinese Academy of Sciences (CAS) (No. KJCX2-SW-H07). The authors thank Dr. Y. F. Men for offering help during the experimental process.

\section{REFERENCES}

1. A. Södegard and M. Stolt, Prog. Polym. Sci., 27, 1123 (2002).

2. R. C. Thomsom, M. C. Wake, M. J. Yaszemski, and A. G. Mikos, Adv. Polym. Sci., 122, 245 (1995).

3. H. D. Kim, E. H. Bae, I. C. Kwon, R. R. Pal, J. D. Nam, and D. S. Lee, Biomaterials, 25, 2319 (2004).

4. Z. Ma, C. Gao, Y. Gong, and J. Shen, Biomaterials, 26, 1253 (2005)

5. T. Yamaoka, Y. Tabata, and Y. Ikada, J. Pharm. Sci., 83, 601 (1994).

6. A. W. Richter and E. Akerblow, Int. Arch. Allergy. Appl. Immunol., 74, 36 (1984).

7. S. Zalipsky, Adv. Drug. Delivery. Rev., 16, 157 (1995).

8. Y. Inada, A. Matsushima, Y. Kodera, and H. J. Nishimura, J. Bioact. Compat. Polym., 5, 3434 (1990).

9. B. R. Greenwald, A. Pendri, and D. Bolikal, J. Org. Chem., 60, 331 (1995).

10. A. Abuchowski, T. van Es, N. C. Palczuk, and F. F. Davis, J. Biol. Chem., 252, 3578 (1977).

11. S. G. Hu and D. H. J. Liu, Macromol. Chem. Phys., 195, 1213 (1994).

12. D. Cohn and H. Younes, J. Biomed. Mater. Res., 22, 993 (1988).

13. D. Cohn and A. Hotovely-Salomon, Polymer, 46, 2068 (2005).
14. R. Gref, Y. Minamitake, M. T. Peracchia, V. Trubetskoy, V. Torchilin, and R. Langer, Science, 263, 1600 (1994).

15. S. A. Hagan, A. G. A. Coombes, M. C. Garnett, S. E. Dunn, M. C. Davies, L. Illum, and S. S. Davis, Langmuir, 12, 2153 (1996).

16. C. He, J. Sun, T. Zhao, Z. Hong, X. Zhuang, X. Chen, and X. Jing, Biomacromolecules, 7, 252 (2006).

17. I. W. Hamley, V. Castelletto, R. V. Castillo, A. J. Müller, C. M. Martin, E. Pollet, and P. h. Dubois, Macromolecules, 38, 463 (2005).

18. J. Albuerne, L. Marquez, A. J. Müller, L. M. Marquez, $\mathrm{Ph}$. Degee, Ph. Dubois, V. Castelletto, and I. W. Hamley, Macromolecules, 36, 1633 (2003).

19. S. Nojima, Y. Akutsu, M. Akaba, and S. Tanimoto, Polymer, 46, 4060 (2005).

20. T. Fujiwara, M. Miyamoto, and Y. Kimura, Macromolecules, 33, 2782 (2000).

21. T. Fujiwara and Y. Kimura, Macromol. Biosci., 2, 11 (2002).

22. T. Fujiwara, M. Miyamoto, Y. Kimura, and S. Sakurai, Polymer, 42, 1515 (2001).

23. S. Y. Lee, I. J. Chin, and J. S. Jung, Eur. Polym. J., 35, 2147 (1999).

24. W. Luo, B. J. Li, and S. Wang, Polym. Adv. Technol., 13, 233 (2002).

25. D. Shin, K. Shin, K. A. Aamer, G. N. Tew, and T. P. Russell, Macromolecules, 38, 104 (2005).

26. J. Yang, T. Zhao, J. Cui, L. Liu, Y. Zhou, G. Li, E. Zhou, and X. Chen, J. Polym. Sci., Part B: Polym. Phys., 44, 3215 (2006).

27. C. W. Lee and Y. Kimura, Bull. Chem. Soc. Jpn., 69, 1787 (1996).

28. M. Avrami, J. Chem. Phys., 7, 1103 (1939).

29. U. W. Gedde, "Polymer Physics," Chapman and Hall, London, 1995.

30. B. Wunderlich, "Macromolecular Physics," Academic Press, New York, 1976.

31. P. Cebe and S. D. Hong, Polymer, 27, 1183 (1986).

32. J. D. Hoffman and J. J. Weeks, J. Chem. Phys., 37, 1723 (1962).

33. J. Xu, B. H. Gu, J. J. Zhou, L. Li, Wu J, and M. Kowalczuk, Polymer, 46, 9176 (2005).

34. K. Tashiro, S. Sasaki, Y. Ueno, A. Yoshioka, and M. Kobayashi, Korea Polym. J., 8, 103 (2000).

35. W. C. La, W. B. Liau, and T. T. Lin, Polymer, 45, 3073 (2004).

36. B. Wunderlich, "Macromolecular Physics," Academic Press, New York, 1980.

37. A. Keller, J. Polym. Sci., 39, 151 (1959).

38. J. M. Schultz and D. R. Kinloch, Polymer, 10, 271 (1969).

39. H. D. Keith and F. J. Padden, J. Polym. Sci., 39, 123 (1959).

40. J. D. Hoffman and R. L. Miller, Polymer, 38, 315 (1997).

41. J. I. Jr. Lauritzen and J. D. Hoffman, J. Res. Natl. Bur. Stand., 64A, 73 (1960). 